\title{
Emission patterns of acrylonitrile and styrene around an industrial wastewater treatment plant in Iran
}

\author{
Kh. Zoroufchi Benis ${ }^{1} \cdot$ M. Shakerkhatibi ${ }^{2} \cdot$ R. Yousefi $^{3} \cdot$ D. Kahforoushan ${ }^{1}$ • \\ S. Derafshi ${ }^{4}$
}

Received: 5 April 2016/Revised: 29 May 2016/Accepted: 27 June 2016/Published online: 20 July 2016

(C) Islamic Azad University (IAU) 2016

\begin{abstract}
The uncontrolled releases of volatile organic compounds (VOCs) from wastewater treatment plants (WWTPs) have been highly concerned due to the associated public health risks. In petrochemical industries, WWTPs are responsible for various organic compound emissions into the atmosphere, which can considered as the main source of VOCs emission in such industries. The typical high-strength petrochemical wastewater is generated from an acrylonitrile-butadiene-styrene (ABS) resin manufacturing plant that usually needs pretreatment before discharging to the main WWTP. The objective of this study was to investigate the emissions and fates of acrylonitrile (ACN) and styrene (STM) through wastewater pretreatment units operated in an ABS manufacturing plant. In this study, the emission rates of ACN and STM were estimated by means of EPA's Water9 emission model. Subsequently, the emission rates were used as the input data of AERMOD model to simulate the atmospheric behaviors of emitted ACN and STM. The results of Water9 model showed that 57 and $81 \%$ of influent ACN and STM are emitted to the air through pretreatment units, respectively. For both of them, the equalization basin had the major portion of
\end{abstract}

M. Shakerkhatibi

shakerkhatibim@tbzmed.ac.ir

1 Faculty of Chemical Engineering, Sahand University of Technology, Tabriz, Iran

2 Department of Environmental Health Engineering, Faculty of Health Sciences, Tabriz University of Medical Sciences, Tabriz, Iran

3 Student Research Committee, Tabriz University of Medical Sciences, Tabriz, Iran

4 Office of Health, Safety and Environment, Tabriz Petrochemical CO., Tabriz, Iran emission to the atmosphere. The concentration distribution profiles of ACN and STM resulted from AERMOD model indicted that the concentration of STM was lower than EPA reference concentration (RfC); however, the higher concentration of ACN (higher than RfC) occurred near the WWTP as well as the neighbor ambient.

Keywords Styrene $\cdot$ Acrylonitrile $\cdot$ Wastewater treatment plant $\cdot$ Dispersion modeling

\section{Introduction}

Volatile organic compounds (VOCs) defined as organic chemical compounds with initial boiling point less than or equal to $250{ }^{\circ} \mathrm{C}$ are composed mainly of carbon and hydrogen that have a high vapor pressure at ordinary room temperature. The high volatility of these compounds leads to significant evaporative emission into the atmosphere under the normal atmospheric conditions (Jiang et al. 2014; Chen et al. 2014; USEPA 2015). Besides their long- and short-term adverse health effects, VOCs have caused increasing concerns due to their detrimental effects on the environment such as destruction of stratospheric ozone layer, formation of photochemical smog and tropospheric ozone, and enhancement of the global greenhouse effect (Kiurski et al. 2016; Venkanna et al. 2014; Cetin et al. 2003). Emissions of VOCs from various sources and their impacts on the environment and public health have been studied in the literature. The studies were focused on both urban and industrial sources such as indoor sources (Liu and Zhu 2014; Cao et al. 2013), landfills (Abdul-Wahab et al. 2016; Majumdar and Srivastava 2012), mobile sources (Roy and Choi 2015; Pang et al. 2015), petrochemical industries (Mo et al. 2015; Cetin et al. 2003), and 
wastewater treatment plants (Chen et al. 2014, 2013; Yang et al. 2012; Fabiyi et al. 2012).

Currently, there has been a growing concern by public and local agencies worldwide regarding the emissions of VOCs from WWTPs. Consequently, several researchers have investigated the VOCs concentrations around WWTPs. Zarra et al. (2014) compared the performance of odor measurement methods including GC-MS, dynamic olfactometry, and electronic nose to identify and characterize the odor emissions from a municipal wastewater treatment plant (MWWTP). Chen et al. (2014) and Chen et al. (2013) investigated the fates of VOCs in the laboratory-scale biological treatment processes with respect to the differences among the species, effects of aeration, and sludge addition. Their findings indicated that the properties of VOCs such as the Henry's law coefficients, volatility, polarity, and biodegradability are the most important factors to determine their fates in the aerobic biological treatment processes. Huang and Wang (2013) carried out a quantitative analysis on the emission and distribution of VOCs (BTEX and chlorinated hydrocarbon) emitted from a MWWTP. Yang et al. (2012) studied the relationship between the VOCs emission rates and the associated cancer and non-cancer risks in the MWWTP. They studied the effects of treatment technologies, VOC species, and seasonal variation on the health risks and emission rates. Oskouie et al. (2008) developed a linear correlations between wastewater treatment process parameters (e.g., flow rate, VOC concentration, and temperature) to shorten the computational time for calculating of VOCs emission rate by BASTE model. This methodology was applied to a MWWTP in Chicago.

Emissions from WWTPs depend on the nature of wastewater and the treatment processes. The emission rates are controlled by both diffusive and convective mechanisms and operational parameters such as concentration gradients between water surface and the ambient air, temperature, detention times, surface area, and the type of treatment application (e.g., aeration and stripping) (Yang et al. 2012; Capelli et al. 2009).

Petrochemical industries are responsible for emission of various organic compounds into the atmosphere, mainly originating from WWTPs, point sources, e.g., leakages from equipment (i.e., fugitive emissions), storage tanks, and loading/unloading operations (Mihajlović et al. 2016; Mo et al. 2015; Shakerkhatibi et al. 2012; Cetin et al. 2003). The specific characteristics of petrochemical WWTP such as high wastewater temperature and high water-phase VOCs concentration in the inlet flow have made them the main source of VOC emissions (Mo et al.
2015; Wei et al. 2014; Tata et al. 2003). One of the typical high-strength petrochemical wastewater is generated from an acrylonitrile-butadiene-styrene (ABS) resin manufacturing plant (Lai et al. 2012b; Shakerkhatibi et al. 2010). The various types of ABS resin are produced using the emulsion grafting-blend production method in the most of the ABS resin plants (Lai et al. 2012a). Even if the polymerizations processes were substantially complete, there would be an undesirable amount of unpolymerized component and suspended solids in an ABS wastewater stream. By considering the high concentration of total suspended solids (TSS) in such stream, a wastewater pretreatment plant is usually used to remove the suspended solids and reduce chemical oxygen demand (COD) before discharging the wastewater to the main WWTP. Large amount of acrylonitrile (ACN) and styrene (STM) is emitted to the atmosphere from such pretreatment plant.

The objective of this study was to investigate the fate of ACN and STM in the ABS wastewater pretreatment plant of Tabriz Petrochemical Company (TPC). In the first step, the concentration of ACN and STM in the wastewater streams was measured using GC method. The measured concentration and operational data of WWTP were used as the input of Water9 model to determine the emission rates and fates of pollutants. Finally, the calculated emission rates were used to find dispersion patterns of pollutants concentration in the study area using AERMOD model.

\section{Materials and methods}

\section{Location and technical characteristics of the WWTP}

The TPC is located in the northwest of Iran, southern west of Tabriz city, next to Tabriz oil Refining Company (Fig. 1). This company mainly produces chemical and polymer materials such as polyethylene, polystyrene, and ABS.

The ABS plant, with the annual capacity of 35,000 tons, uses emulsion grafting-blend production technology to produce various types of ABS resin. The feed of this process consists of styrene, acrylonitrile, and hundreds of auxiliary agents, which leads to a toxic, refractory, and complicated ABS resin wastewater. Considering the presence of toxic substance such as the aromatic compounds and organic nitriles in the wastewater effluent of ABS plants, conventional biological treatment processes cannot easily mineralize all of these pollutants (Lai et al. 2013). Therefore, the wastewater generated in ABS plant of TPC is pretreated using activated sludge process (ASP) as in- 


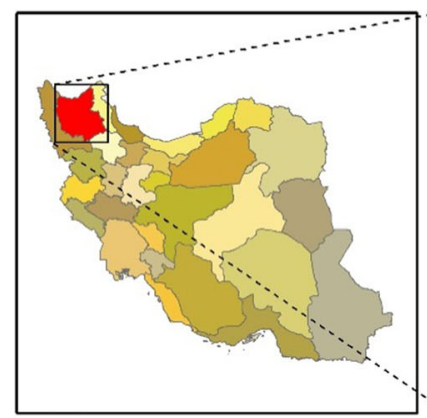

IRAN

East Azerbaijan

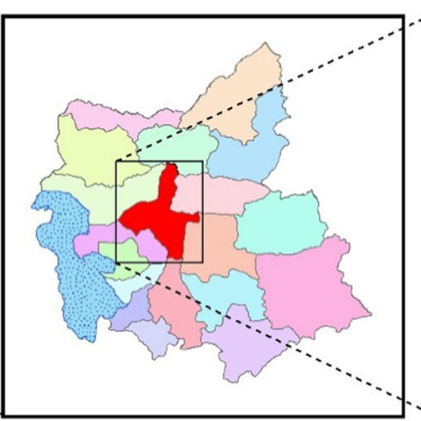

East Azerbaijan Tabriz County

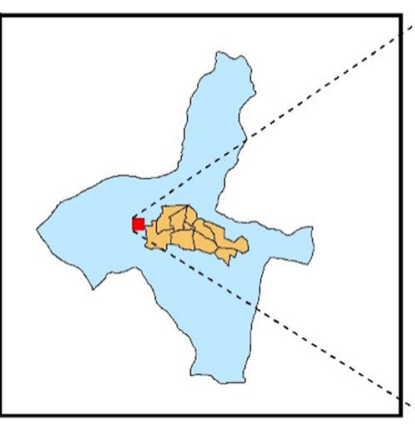

Tabriz County

- Study Area

Tabriz City

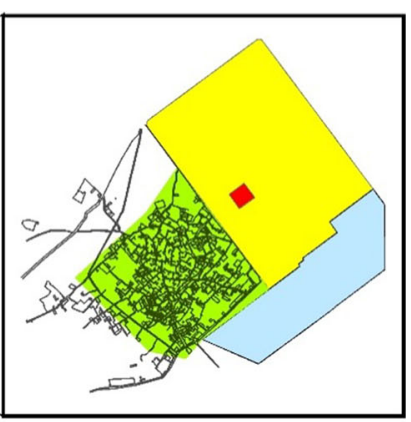

Study Area

$\square$ Tabriz Petrochemical Company $\square$ Tabriz Oil Refining Company $\square$ Kojabad Village

aBS Plant

Fig. 1 Location of the study area

Fig. 2 Schematic flow diagram of ABS wastewater pretreatment plant

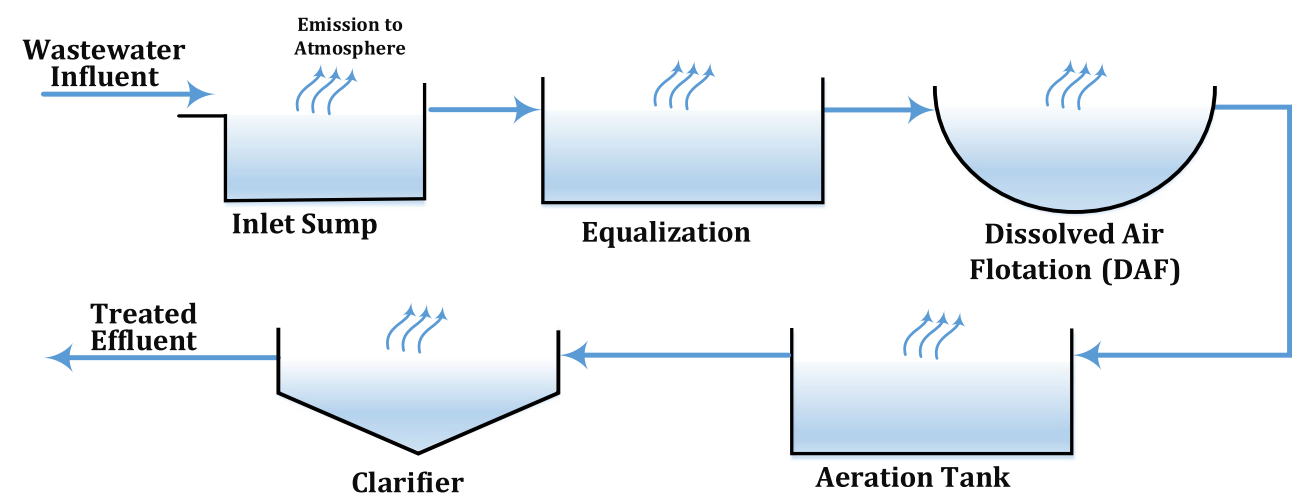

plant control system prior to discharge to the main WWTP. The duties of this plant are the as possible as elimination of suspended solids and the reduction in COD. Figure 2 schematically depicts the process diagram of $\mathrm{ABS}$ wastewater pretreatment plant.

\section{Estimation of VOC emission rates}

Estimating VOC emissions from WWTPs can be obtained by using models, emission factors, and direct measurements (Tata et al. 2003). Direct measurement of emission rates is complex and costly, and it involves a great deal of fieldwork. To overcome these difficulties, the scientific community has developed various mathematical models such as US Environmental Protection Agency Water9 (USEPA), Toxchem (Environmega), and BASTE (Bay Area Air Toxics Group) to determine the fate of VOCs and their emission rates (Zhang 2010; Yang et al. 2012; Carrera-Chapela et al. 2014). These models developed mainly based on the mass balance for each operation units in a WWTP. Generally, determining the fate of pollutants and calculating the pollutants concentration in any given operation unit are based on the modeling of processes for volatilization, adsorption, absorption, stripping, and biodegradation as a function of concentration, operation conditions, and kinetics parameters such as mass transfer coefficient and Henry's law constant (Zhang 2010; Kemp et al. 2002). As an example, the mass balance in a wastewater treatment system can be expressed as Eq. 1 (Zhang 2010):

$V \frac{\mathrm{d} c}{\mathrm{~d} t}=Q C_{0}-Q C+R_{\mathrm{V}}+R_{\mathrm{S}}+R_{\mathrm{ad}}+R_{\mathrm{ab}}+R_{\mathrm{b}}$

where $V$ is operational volume of the system $\left(\mathrm{m}^{3}\right) ; \mathrm{d} c / \mathrm{d} t$ is the changing rate of dissolved compound concentration $\left(\mathrm{mg} / \mathrm{m}^{3} \mathrm{~s}\right)$ which is zero under steady-state condition; $Q$ is the flow rate entering the operation unit $\left(\mathrm{m}^{3} / \mathrm{s}\right) ; C_{0}$ and $C$ are the dissolved compound concentration entering and leaving the operation unit, respectively $\left(\mathrm{mg} / \mathrm{m}^{3}\right)$; and $R_{\mathrm{V}}$, $R_{\mathrm{S}}, R_{\mathrm{ad}}, R_{\mathrm{ab}}, R_{\mathrm{b}}$ are the compound removal rate by volatilization, stripping, adsorption, absorption, and biodegradation, respectively $(\mathrm{mg} / \mathrm{s})$. 
In this study, EPA's Water9 model version 3, which is widely used in several studies (Santos et al. 2012; Zhang 2010; Fatehifar et al. 2008; Aneja et al. 2006), was applied to estimate emission rates of STM and ACN from different operation units as indicated in Fig. 2. Water9 requires input information on wastewater condition (i.e., $\mathrm{pH}$, temperature, flow rate, pollutant concentration, and TSS) and layout/unit process-specific data such as meteorological parameters, liquid depth, surface area, and agitation data (WATER 2001). Water9 determines the mass transfer coefficient for the liquid phase with taking account of wind speed, fetchto-depth ratio, and molecular diffusivity of the chemical in the water or the Schmidt number for the liquid phase. Also, the mass transfer coefficient for the gas phase depends on the Schmidt number of the gas phase, wind speed, and the free surface area (Santos et al. 2012).

\section{Dispersion model}

Atmospheric dispersion models can be used to examine atmospheric dispersion of pollutants emitted from many various sources. AERMOD was used to model atmospheric dispersion of STM and ACN in the study area. The AERMOD atmospheric dispersion modeling system which is developed by the American Meteorological Society and the US Environmental Protection Agency is a steady-state dispersion model for research and regulatory applications, and it can be used for single or multiple point, area and volume sources (Jafarigol et al. 2015; Huertas et al. 2012).

The information needed for the model includes three categories: emissions, meteorology, and terrain. The output results of Water9 model were used as the emissions data. AERMET and AERMAP sub-models, respectively, to prepare these data in a format readable by AERMOD, processed meteorological and terrain data. AERMET is a preprocesser, which calculates boundary layer parameters and provides the meteorological variables in the required format for AERMOD. Input data for AERMET include hourly cloud cover observations, surface meteorological observations (such as wind speed and direction, humidity, temperature, dew point, and sea level pressure), surface data (such as surface roughness, Bowen ratio, and albedo), and upper air soundings. AERMAP uses gridded terrain data (digital elevation model data) of the domain to calculate the representative terrain-influence height associated with each receptor's location (USEPA 2004, 2009). The AERMOD modeling system, used in this study, was run with a graphical interface, AERMOD View (version 5.8.1) (Lakes Environmental Software, Waterloo, Ontario, Canada).

The hourly sequential meteorological data (year 2015) registered at a closest weather station of Tabriz Meteorological Organization were used as the input data to AERMET preprocesser. Wind velocity and direction as well as the air temperature are the meteorological parameters that impose significant effect on the distribution of pollutants (Zoroufchi Benis and Fatehifar 2015). The study area wind rose in yearly period is presented in Fig. 3. The wind rose shows that dominant wind directions throughout the study area are eastern $\left(90^{\circ}\right)$, northeastern $\left(45^{\circ}\right)$, and western $\left(270^{\circ}\right)$ winds. Figure 4 shows daily average temperature of the study area. Maximum and minimum temperature
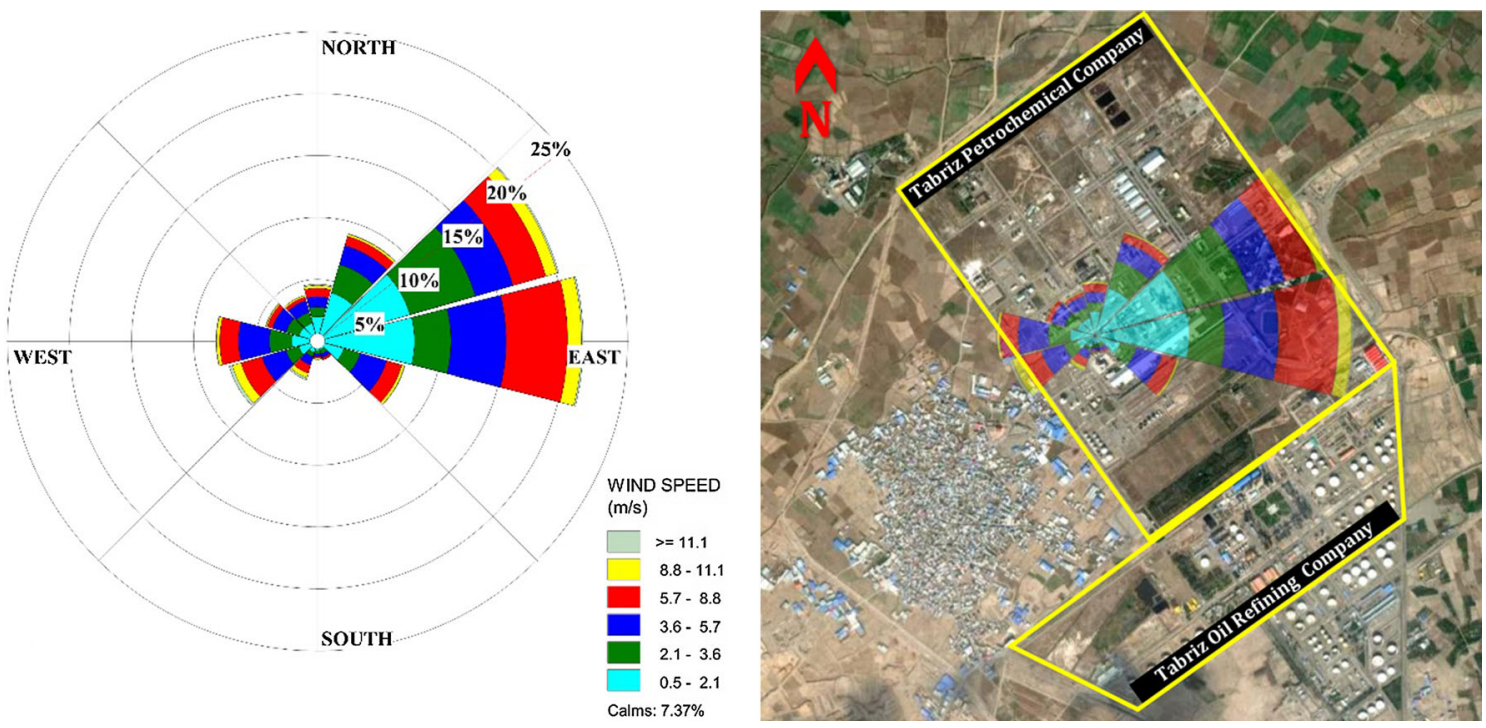

Fig. 3 Wind rose plot in the study area (year 2015) 
Fig. 4 Daily temperature fluctuations over one year (2015)

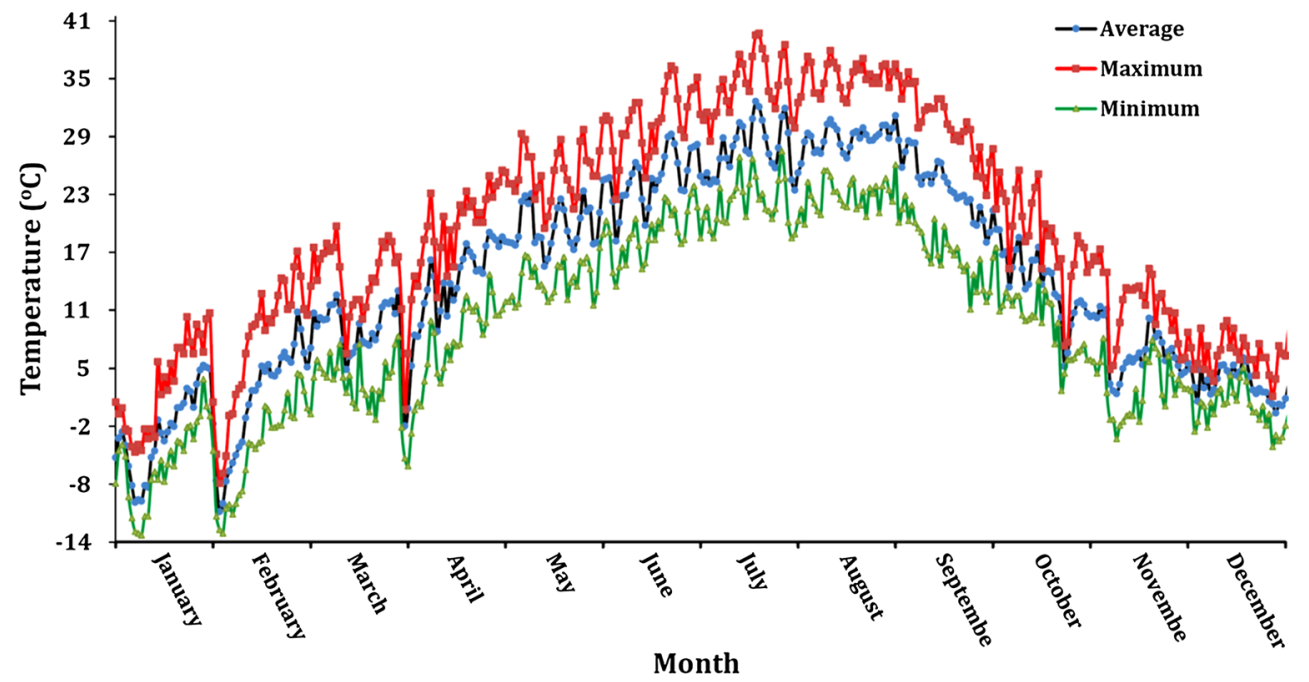

recorded in the study area was 39.2 and $-12.8^{\circ} \mathrm{C}$, respectively.

\section{Analytical methods}

The COD concentrations, $\mathrm{pH}$, and TSS were measured according to standard methods (APHA 2005). The concentration of acrylonitrile and styrene was measured using GC (Agilent-7890A) equipped with a HP-5 capillary column $(30 \mathrm{~m} \times 0.32 \mathrm{~mm})$ with $0.25-\mu \mathrm{m}$ film thickness and a flame ionization detector. To analyze acrylonitrile, the injector was kept at $170{ }^{\circ} \mathrm{C}$, the column was programmed from 40 to $230{ }^{\circ} \mathrm{C}$ at $40{ }^{\circ} \mathrm{C} / \mathrm{min}$ increments ( 3 min hold), and the detector was set at $230{ }^{\circ} \mathrm{C}$. To analyze styrene, the temperature was programmed from $40{ }^{\circ} \mathrm{C}$ (1 min) to $100{ }^{\circ} \mathrm{C}$ at $20^{\circ} \mathrm{C} / \mathrm{min}$, keeping this temperature for $1 \mathrm{~min}$. The detector and injector temperature were set to 300 and $230{ }^{\circ} \mathrm{C}$, respectively.

\section{Results and discussion}

\section{Fate of ACN and STM}

Water9 model requires two types of input data for estimation of emission rates: (1) changing variables and (2) constant parameters. Changing variables are those that may change over the time due to the variation of operational conditions in ABS plant such as wastewater flow rate. Constant parameters generally are physical properties of WWTP. In this study, the average value of changing variables was used in the model. Table 1 shows the required input data (changing variables) of the Water9 model which were measured in the influent stream over the study period (year 2015).

Air emissions from each operation unit indicated in Fig. 2 were estimated as emission rates of ACN and STM (Table 2). Overall emission of ACN and STM from WWTP was 130,131 g/day from which 64 and $36 \%$ are belonged to ACN and STM, respectively. The emission percentage from each operation unit is presented in Fig. 5. The highest emission of both ACN and STM was estimated from equalization basin, which is due to the high concen-

Table 2 Estimated air emission rates

\begin{tabular}{lcc}
\hline Unit & $\begin{array}{l}\text { Acrylonitrile } \\
\text { Emission rate (g/day) }\end{array}$ & $\begin{array}{l}\text { Styrene } \\
\text { Emission rate (g/day) }\end{array}$ \\
\hline Inlet sump & 82.3 & 51.0 \\
Equalization basin & 73094.4 & 23846.4 \\
DAF & 9331.2 & 21945.6 \\
Aeration basin & 1123.2 & 224.6 \\
Clarifier & 259.2 & 172.8 \\
Total emission & 83890.3 & 46240.4 \\
\hline
\end{tabular}

Table 1 Characteristics of the influent wastewater

\begin{tabular}{llllllll}
\hline Qave $\left(\mathrm{m}^{3} / \mathrm{d}\right)$ & $\mathrm{pH}$ & Oil/grease $(\mathrm{mg} / \mathrm{l})$ & $\mathrm{COD}(\mathrm{mg} / \mathrm{l})$ & $\mathrm{TSS}(\mathrm{mg} / \mathrm{l})$ & Temperature $\left({ }^{\circ} \mathrm{C}\right)$ & Acrylonitrile Conc. $(\mathrm{ppm})$ & Styrene Conc. $(\mathrm{ppm})$ \\
\hline 469 & 6.4 & 0 & 1345 & 649 & 34.5 & 314 & 123 \\
\hline
\end{tabular}


Fig. 5 Percentage share of each operation unit emission a acrylonitrile, b styrene

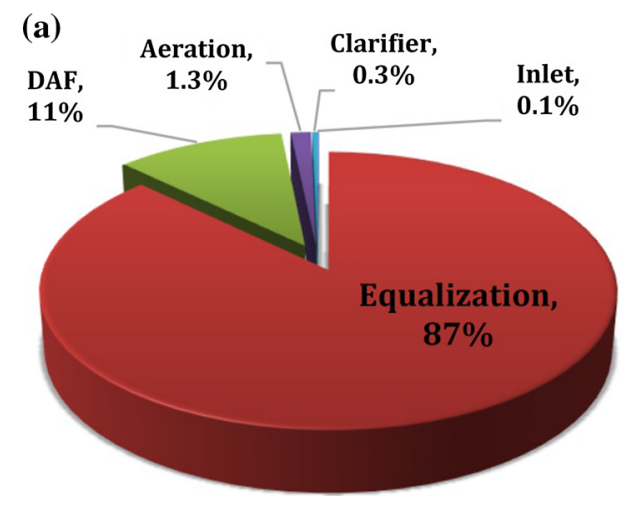

tration and large surface area for evaporation in the basin (Yang et al. 2012, 2014). Dissolved Air Flotation (DAF) unit was the second major source of ACN and STM. The higher volatility (lower boiling point) of ACN compared to STM increases the chance of ACN for emission to air, so the large portion of ACN (87\%) was evaporated in the first operation unit (equalization basin); however, STM had less opportunity for evaporation in the equalization basin, so $47 \%$ of STM was emitted from DAF. The air emissions from three last operation units were low in compared to equalization basin, DAF that is especially due to low water-phase ACN and STM concentrations, and biological degradation potential.

The overall mass balance of considered pollutants is presented in Table 3. The high removal fraction of ACN indicates that the WWTP has better capability to remove the ACN than STM. This property leads to effective reduction of air emission and the $\mathrm{ACN}$ concentration in the effluent, so that only $57 \%$ of ACN in the influent entered to the atmosphere. Conversely, in the case of STM, low

Table 3 Fate of ACN and STM (overall mass balance)

\begin{tabular}{llll}
\hline Parameter & Fraction & & \\
\cline { 2 - 4 } & To the air & Removal & In the effluent \\
\hline Acrylonitrile & 0.57 & 0.36 & 0.07 \\
Styrene & 0.81 & 0.06 & 0.13 \\
\hline
\end{tabular}

removal efficiency of WWTP resulted in higher air emission of $87 \%$.

\section{Evaluation of accuracy of the model}

For evaluation of accuracy of the Water9 model, estimated values of ACN and STM in the outlet flow of operation units were compared with measured concentrations. ACN was measured in the outlet flow of equalization, DAF, and clarifier (plant outlet), and STM was measured in the plant outlet. Table 4 shows the comparison results between the estimated and measured values. As indicated in the table, the average error was about $6 \%$, and it is believed that lower than $10 \%$ error in emission factor estimation is very good (Fatehifar et al. 2008). This result indicates that estimation error of Water9 model increases with decreasing of compound concentration (Fatehifar et al. 2008; Santos et al. 2012); however, this model provides realistic estimates of volatilization of VOCs.

\section{Dispersion of ACN and STM}

The VOCs emitted from the WWTP have the potential of adverse impacts on the nearby environment and public health. Besides the adverse health effects on laborers working in the plants, the pollutants may be dispersed and transported to long distances which leads to health risks of the public in the nearby environment.

Table 4 Comparison of the results between the estimated (Water9) and measured values

\begin{tabular}{|c|c|c|c|c|c|c|c|c|c|}
\hline & \multicolumn{3}{|c|}{ Equalization outlet } & \multicolumn{3}{|c|}{ DAF outlet } & \multicolumn{3}{|c|}{ Plant outlet } \\
\hline & $\begin{array}{l}\text { Estimated } \\
(\mathrm{ppm})\end{array}$ & $\begin{array}{l}\text { Measured } \\
(\mathrm{ppm})\end{array}$ & $\begin{array}{l}\text { Error } \\
(\%)\end{array}$ & $\begin{array}{l}\text { Estimated } \\
(\mathrm{ppm})\end{array}$ & $\begin{array}{l}\text { Measured } \\
(\mathrm{ppm})\end{array}$ & $\begin{array}{l}\text { Error } \\
(\%)\end{array}$ & $\begin{array}{l}\text { Estimated } \\
(\mathrm{ppm})\end{array}$ & $\begin{array}{l}\text { Measured } \\
(\mathrm{ppm})\end{array}$ & $\begin{array}{l}\text { Error } \\
(\%)\end{array}$ \\
\hline Acrylonitrile & 136 & 131 & 3.8 & 117 & 110 & 6.6 & 20 & 19 & 7.1 \\
\hline Styrene & & & & & & & 15 & 16 & 6.4 \\
\hline
\end{tabular}




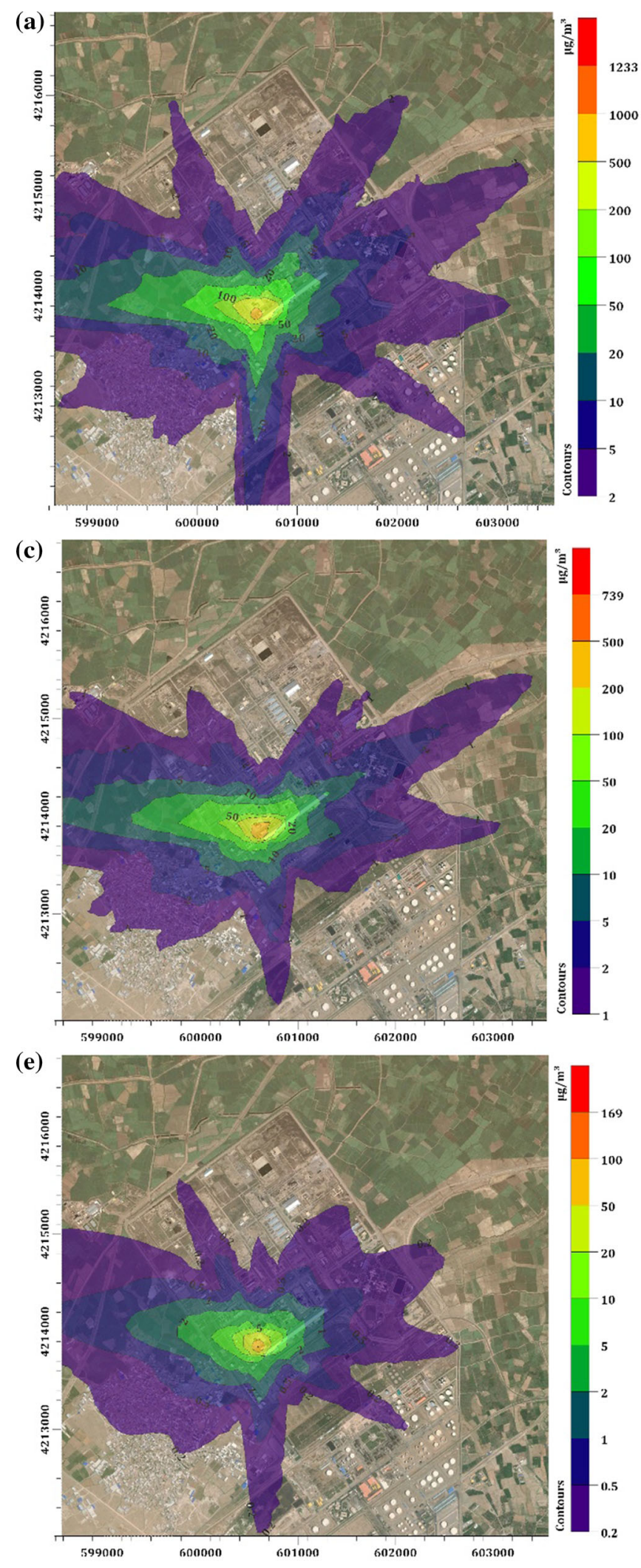

Fig. 6 Distribution patterns of pollutants around the WWTP a maximum 1-h average concentration of $\mathrm{ACN}$, b maximum 1-h average concentration of STM, c maximum 24-h average concentration of
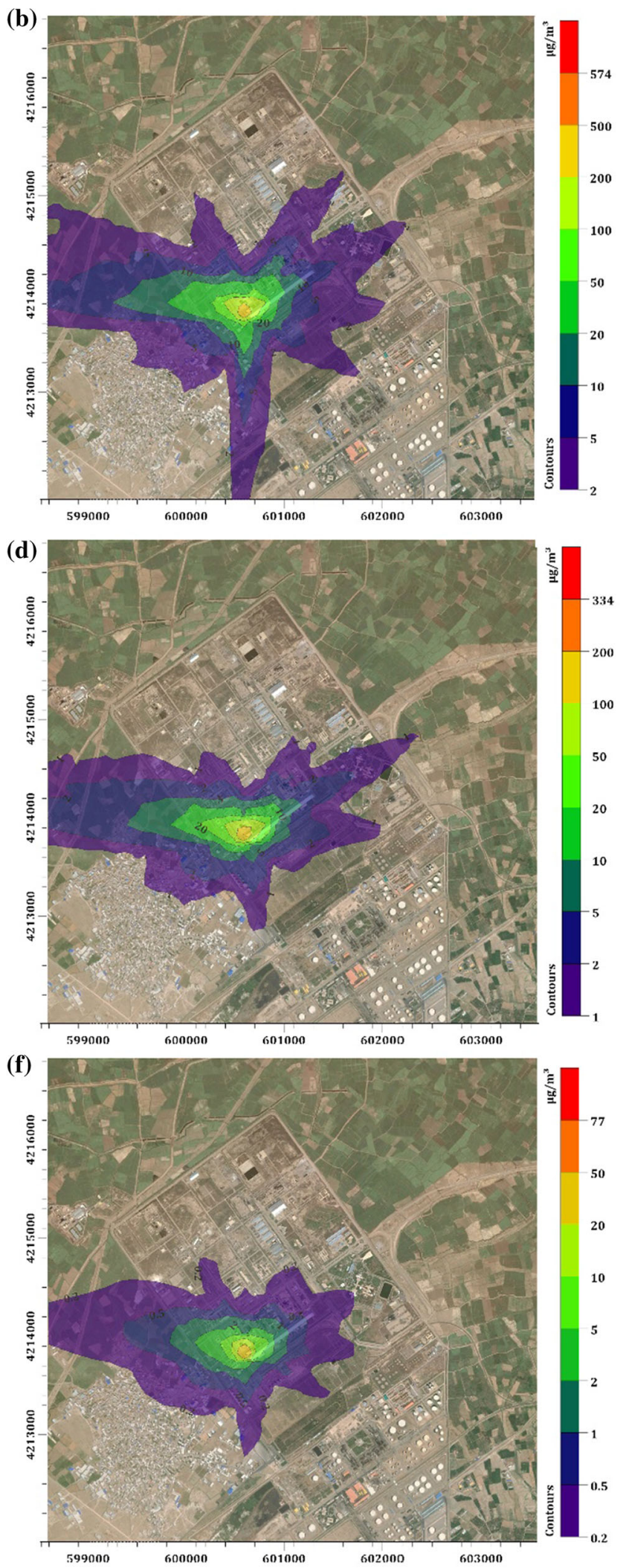

ACN, $\mathbf{d}$ maximum 24-h average concentration of STM, e total period average concentration of $\mathrm{ACN}$, and $\mathbf{f}$ total period average concentration of STM 
AERMOD model was used to simulate the atmospheric behaviors of the VOCs emitted from the operational units of WWTP. The modeling was done on a rectangular gridded area $(5 \times 5 \mathrm{~km})$ around the sources, so that the plant workers and nearby village were covered. The model was set up to simulate the ACN and STM ground-level concentrations, resulting from all the 5 area sources at gridded area based on maximum 1-h average concentration, maximum 24-h average concentration, and total period average concentration. The emission rates resulted from Water9 model were used as the input data of AERMOD.

Figure 6 shows the results of simulation of pollutants dispersion around WWTP. The patterns of distribution show that the maximum concentrations of both ACN and STM were occurred inside the fence of TPC and near the WWTP. For all three cases of averaging time (1, $24 \mathrm{~h}$ and period), the maximum concentration of $\mathrm{ACN}$ was higher than STM which was due to the higher emission rate of ACN compared to STM. However, both pollutants had almost the same concentration distribution profiles over the study area. The distribution profile of maximum 1-h average concentration of pollutants showed a maximum value of 1233 and $574 \mu \mathrm{g} / \mathrm{m}^{3}$ for ACN and STM, respectively. Considering the low release height of emission sources, pollutants cannot be transported far from the emission sources, so the maximum concentrations were occurred near the sources. The EPA reference concentration (RfC) for styrene and acrylonitrile is 1000 and $2 \mu \mathrm{g} /$ $\mathrm{m}^{3}$, respectively. Comparison of STM concentration with $\mathrm{RfC}$ indicated that the maximum concentration of STM (emitted from WWTP) was lower than RfC in the various considered cases of averaging time. In the case of ACN, the concentration in all of averaging time cases was higher than $2 \mu \mathrm{g} / \mathrm{m}^{3}$ inside the fence of TPC. However, the total period average concentration of ACN was lower than RfC over the neighbor village.

\section{Conclusion}

The present study was conducted to evaluate the emission pattern of styrene and acrylonitrile emitted from an ABS wastewater pretreatment plant in Iran. EPA's Water9 model was applied to estimate the emission rates of both pollutants. The results indicated that the Water9 model has good estimation performance. The findings showed that a large portion of VOCs entered to WWTP and emitted to atmosphere. The resulted emission rates from Water9 model were used as the input data for AERMOD dispersion model to find the patterns of pollutants distribution around the WWTP. Considering the results of this model, it can be concluded that styrene concentrations in different averaging times (1-h, 24-h, and total period) were lower than RfC all over the study area. Given the low RfC value for acrylonitrile, high concentrations can occur in the neighbor village of TPC. However, the concentration of acrylonitrile was higher than RfC near the WWTP.

Acknowledgments The authors acknowledge the help and support provided by the HSE department of TPC. There was no funding for this study. The authors also confirm that there is no competing interest for this research. The local ethical review committee of the Tabriz University of Medical Sciences approved the study (Ethical No. $\mathrm{B} / 257)$.

\section{Compliance with ethical standards}

Conflict of interest The authors also confirm that there is no competing interest for this research.

\section{References}

Abdul-Wahab SA, Al-Hajri A, Yetilmezsoy K (2016) Impact of the ambient air quality due to the dispersion of non-methane organic compounds from Barka Landfill. Int J Environ Sci Technol. doi:10.1007/s13762-016-0947-x

Aneja VP, Blunden J, Claiborn CS, Rogers HH (2006) Dynamic chamber system to measure gaseous compounds emissions and atmospheric-biospheric interactions. In: Barnes I, Rudzinski KJ (eds) Environmental simulation chambers: application to atmospheric chemical processes. Springer, Dordrecht, pp 97-109. doi:10.1007/1-4020-4232-9_7

APHA (2005) Standard methods for the examination of water and wastewater, 22nd edn. American Public Health Association, Washington DC

Cao J, Deng B, Kim CN (2013) Effect of VOCs-adsorbing particles on the VOCs emission from wood. Int $J$ Heat Mass Transf 61:721-728. doi:10.1016/j.ijheatmasstransfer.02.040

Capelli L, Sironi S, Del Rosso R, Céntola P (2009) Predicting odour emissions from wastewater treatment plants by means of odour emission factors. Water Res 43(7):1977-1985

Carrera-Chapela F, Donoso-Bravo A, Souto JA, Ruiz-Filippi G (2014) Modeling the odor generation in WWTP: an integrated approach review. Water Air Soil Pollut 225(6):1-15. doi:10. 1007/s11270-014-1932-y

Cetin E, Odabasi M, Seyfioglu R (2003) Ambient volatile organic compound (VOC) concentrations around a petrochemical complex and a petroleum refinery. Sci Total Environ 312(1):103-112

Chen W-H, Yang W-B, Yuan C-S, Yang J-C, Zhao Q-L (2013) Influences of aeration and biological treatment on the fates of aromatic VOCs in wastewater treatment processes. Aerosol Air Qual Res 13:225-236 
Chen W-H, Yang W-B, Yuan C-S, Yang J-C, Zhao Q-L (2014) Fates of chlorinated volatile organic compounds in aerobic biological treatment processes: The effects of aeration and sludge addition. Chemosphere 103:92-98. doi:10.1016/j.chemosphere.2013.11. 039

Fabiyi M, Goel R, Snowling S, Novak R (2012) Reduction of VOC emissions in high purity oxygen activated sludge wastewater treatment process: toxchem based fate and emissions modeling case study. In: AIChE annual meeting, conference proceedings, 2012

Fatehifar E, Kahforoshan D, Khazini L, Soltanmohammadzadeh J, Sattar H (2008) Estimation of VOC emission from wastewater treatment unit in a petrochemical plant using emission factors. In: WSEAS Conferences, Santander, Spain 2008. pp 23-25

Huang LK, Wang GZ (2013) Study on species and distribution of volatile organic compounds in WWTP. In: advanced materials research, 2013. Trans Tech Publ, pp 2035-2038

Huertas JI, Huertas ME, Díaz J (2012) Assessing precision and accuracy of atmospheric emission inventories. Int J Environ Sci Technol 9(2):195-202. doi:10.1007/s13762-012-0022-1

Jafarigol F, Atabi F, Moattar F, Nouri J (2015) Predicting ambient concentrations of $\mathrm{NO}_{2}$ in a gas refinery located in South Pars Gas Complex. Int J Environ Sci Technol 13(3):897-906. doi:10. 1007/s13762-015-0870-6

Jiang Z, Chen M, Shi J, Yuan J, Shangguan W (2014) Catalysis removal of indoor volatile organic compounds in room temperature: from photocatalysis to active species assistance catalysis. Catal Surv Asia 19(1):1-16. doi:10.1007/s10563-014-9177-8

Kemp J, Zytner RG, Sterne L, Rittmann BE (2002) Measuring and modelling VOC biotransformation rates. Environ Technol 23(5):547-551. doi:10.1080/09593332308618389

Kiurski JS, Marić BB, Aksentijević SM, Oros IB, Kecić VS (2016) Occupational hazards in printing industry. Int J Environ Sci Technol 13(3):955-972. doi:10.1007/s13762-016-0937-z

Lai B, Zhou Y, Qin H, Wu C, Pang C, Lian Y, Xu J (2012a) Pretreatment of wastewater from acrylonitrile-butadiene-styrene (ABS) resin manufacturing by microelectrolysis. Chem Eng J 179:1-7. doi:10.1016/j.cej.2010.12.089

Lai B, Zhou Y, Yang P, Wang K (2012b) Comprehensive analysis of the toxic and refractory pollutants in acrylonitrile-butadiene-styrene resin manufacturing wastewater by gas chromatography spectrometry with a mass or flame ionization detector. J Chromatogr A 1244:161-167. doi:10.1016/j. chroma.2012.04.058

Lai B, Zhou Y, Yang P (2013) Treatment of wastewater from acrylonitrile-butadiene-styrene (ABS) resin manufacturing by biological activated carbon (BAC). J Chem Technol Biotechnol 88(3):474-482. doi:10.1002/jctb.3856

Liu Y, Zhu X (2014) Measurement of formaldehyde and VOCs emissions from wood-based panels with nanomaterial-added melamine-impregnated paper. Constr Build Mater 66:132-137. doi:10.1016/j.conbuildmat.2014.05.088

Majumdar D, Srivastava A (2012) Volatile organic compound emissions from municipal solid waste disposal sites: a case study of Mumbai, India. J Air Waste Manag Assoc 62(4):398-407. doi:10.1080/10473289.2012.655405

Mihajlović M, Jovanović M, Pešić R, Jovanović J, Milanović Z (2016) Volatile organic compounds (VOC) policy innovation in petrochemicals river barge transportation. J Clean Prod 112 Part 2:1559-1567. doi:10.1016/j.jclepro.2015.04.080
Mo Z, Shao M, Lu S, Qu H, Zhou M, Sun J, Gou B (2015) Processspecific emission characteristics of volatile organic compounds (VOCs) from petrochemical facilities in the Yangtze River Delta, China. Sci Total Environ 533:422-431. doi:10.1016/j. scitotenv.2015.06.089

Oskouie AK, Lordi DT, Granato TC, Kollias L (2008) Plant-specific correlations to predict the total VOC emissions from wastewater treatment plants. Atmos Environ 42(19):4530-4539. doi:10. 1016/j.atmosenv.2008.01.062

Pang Y, Fuentes M, Rieger P (2015) Trends in selected ambient volatile organic compound (VOC) concentrations and a comparison to mobile source emission trends in California's South Coast Air Basin. Atmos Environ 122:686-695. doi:10.1016/j. atmosenv.2015.10.016

Roy A, Choi Y (2015) Temperature dependence of source specific volatility basis sets for motor vehicle exhaust. Atmos Environ 119:258-261. doi:10.1016/j.atmosenv.2015.08.035

Santos JM, Kreim V, Guillot J-M, Reis NC Jr, de Sá LM, Horan NJ (2012) An experimental determination of the $\mathrm{H}_{2} \mathrm{~S}$ overall mass transfer coefficient from quiescent surfaces at wastewater treatment plants. Atmos Environ 60:18-24. doi:10.1016/j. atmosenv.2012.06.014

Shakerkhatibi M, Ganjidoust H, Ayati B, Fatehifar E (2010) Performance of aerated submerged fixed-film bioreactor for treatment of acrylonitrile-containing wastewater. Iran J Environ Health Sci Eng 7(4):327

Shakerkhatibi M, Monajemi P, Jafarzadeh MT, Mokhtari SA, Farshchian MR (2012) Feasibility study on EO/EG wastewater treatment using pilot scale SBR. Int J Environ Res 7(1):195-204

Tata P, Witherspoon J, Lue-Hing C (2003) VOC emissions from wastewater treatment plants: characterization, control and compliance. CRC Press

USEPA (2004) AERMOD: Description of model formulation. EPA454/R-03-004. Office of air quality planning and standards, emissions monitoring and analysis division, U.S. Environmental Protection Agency

USEPA (2009) AERMOD implementation guide. office of air quality planning and standards, air quality assessment division, AERMOD implementation workgroup., U.S. Environmental Protection Agency

USEPA (2015) Technical overview of volatile organic compounds. USEPA

Venkanna R, Nikhil GN, Siva Rao T, Sinha PR, Swamy YV (2014) Environmental monitoring of surface ozone and other trace gases over different time scales: chemistry, transport and modeling. Int J Environ Sci Technol. doi:10.1007/s13762-014-0537-8

WATER U (2001) User's guide for WATER9 Software. Office of Air Quality Planning and Standards, USEPA

Wei W, Cheng S, Li G, Wang G, Wang H (2014) Characteristics of volatile organic compounds (VOCs) emitted from a petroleum refinery in Beijing, China. Atmos Environ 89:358-366. doi:10. 1016/j.atmosenv.2014.01.038

Yang W-B, Chen W-H, Yuan C-S, Yang J-C, Zhao Q-L (2012) Comparative assessments of VOC emission rates and associated health risks from wastewater treatment processes. J Environ Monit 14(9):2464-2474. doi:10.1039/C2EM30138E

Yang J, Wang K, Zhao Q, Huang L, Yuan C-S, Chen W-H, Yang W-B (2014) Underestimated public health risks caused by overestimated VOC removal in wastewater treatment processes. 
Environ Sci Process Impacts 16(2):271-279. doi:10.1039/ C3EM00487B

Zarra T, Reiser M, Naddeo V, Belgiorno V, Kranert M (2014) Odour emissions characterization from wastewater treatment plants by different measurement methods. Chem Eng Trans 40:37-42
Zhang K (2010) Characterization and uncertainty analysis of VOCs emissions from industrial wastewater treatment plants. Environ Prog Sustain Energy 29(3):265-271

Zoroufchi Benis K, Fatehifar E (2015) Optimal design of air quality monitoring network around an oil refinery plant: a holistic approach. Int J Environ Sci Technol 12(4):1331-1342. doi:10. 1007/s13762-014-0723-8 